\title{
Effect of Cooking Condition on the Water-Soluble Flavor Precursors in Various Beef Muscles from Hanwoo (Korean Cattle)
}

\author{
Sun Moon Kang, Geunho Kang, Pilnam Seong, Youngchun Kim, Beomyoung Park, and Soohyun Cho* \\ Animal Products Research and Development Division, National Institute of Animal Science, \\ Rural Development Administration, Suwon 441-706, Korea
}

\begin{abstract}
This study was carried out to investigate the effect of cooking condition on the water-soluble flavor precursors relevant to postmortem glycogen metabolisms in various beef muscles from Hanwoo (Korean cattle). The loins, striploins, top rounds, and eye of rounds from 40 -mon-old heifers were cooked in either with $100^{\circ} \mathrm{C}$ water bath (wet-cooking) or $180^{\circ} \mathrm{C}$ household electric oven (dry-cooking) until attained to about $80^{\circ} \mathrm{C}$ of internal temperature before the measurements of amounts of macroglycogen, proglycogen, free glucose, and lactate. The macroglycogen and proglycogen contents were not significant differences in all beef muscles between the wet-cooking and dry-cooking treatments. Regardless of cooking condition, the both loin and top round had higher $(p<0.05)$ two types of glycogen than the eye of round. The free glucose and lactate contents presented higher trends in the dry-cooking treatment compared with the wet-cooking treatment. The wet-cooked top round had higher $(p<0.05)$ free glucose than the wet-cooked eye of round. Moreover, the top round contained the highest lactate content regardless of cooking condition. Consequently, it is considered that the dry-cooking treatment would be more beneficial to the flavor of cooked beef muscles than the wet-cooking treatment.
\end{abstract}

Key words: cooking, flavor precursor, glucose, lactate, beef, Hanwoo

\section{Introduction}

The current trends of meat market have being turned from the quantitative consumption to the qualitative consumption in some of the advanced countries in the world because of economic growth and prevalence of wellbeing and LOHAS (Lifestyle of Health and Sustainability). Simply put, consumers, when buy the meat, consider the quality more important than the quantity. The majority of them, as well, want to purchase the high quality meat despite payment of high prices (Stezer et al., 2008). Eating quality is very closely associated with consumer preference and is mainly dictated by texture, flavor, and juiciness (Savell et al., 1987). Particularly, coupling of aroma with taste, the flavor is the second-most effective factor (Bryhni et al., 2002). In a study on palatability grading model in beef, Cho and co-workers (2008) suggested that flavor accounted for $29.8 \%$ of the rate of total consumer satisfaction when tenderness and juiciness ac-

\footnotetext{
*Corresponding author: Soohyun Cho, Animal Products Research and Development Division, National Institute of Animal Science, Rural Development Administration, Suwon 441-706, Korea. Tel: 82-31-290-1703, Fax: 82-31-290-1697, E-mail: shc0915@korea.kr
}

counted respectively for $51.2 \%$ and $19.0 \%$.

Meat flavor is the chemical product occurred by harmonizing among five fundamental tastes, such as umami, bitterness, saltiness, sweetness, and sourness, and many different volatile compounds developed from endogenous flavor sources in meat, that is, flavor precursors, such as carbohydrates, amino acids, peptides, nucleic acids, and fatty acids (MacLord, 1986; Shahidi, 1998). Among the biochemical components generated by postmortem carbohydrate metabolisms, residual glycogen and glucose bring out the unique aroma by forming maillard reaction compounds with amino acids in cooked meat (Hornstein and Crowe, 1960; Pethick et al., 1995). Also, glucose and lactate contribute the distinct taste to meat (MacLeod, 1994; Mottram, 1991).

Although a variety of factors, including livestock breed, feed, meat quality grade, aging, processing, and cooking, affect the meat flavor (Adhikari et al., 2004; Belk et al., 1993; Calkins, 2002; Koutsidis et al., 2008a, 2008b; MacKenna et al., 2004; Miller et al., 1997; Streff et al., 2003), cooking treatment may be the most effective for the flavor of meat because people usually eat the cooked meat. Cooking treatment significantly alters the composition of flavor precursors in meat (Alfaia et al., 2010; Sasaki et 
al., 2007). Sasaki et al. (2007) found that wet-cooking (water bath-cooking) treatment decreased amounts of total amino acids with glutamic acid, inosine monophosphate, and oligopeptide in pork. Moreover, Alfaia et al. (2010) revealed that boiled, microwaved, or grilled beef contained lower polyunsaturated fatty acids/saturated fatty acids ratio than raw beef. However, up to the present, little information on effect of cooking on the compounds relevant to postmortem glycogen metabolisms has been reported.

Therefore, this study was carried out to investigate the effect of cooking condition on the water-soluble flavor precursors, such as glycogen, glucose, and lactate, in various beef muscles from Hanwoo (Korean cattle).

\section{Materials and Methods}

\section{Reagents and chemicals}

Trizma base, bromothymol blue sodium salt (BTB), phenolphthalein, glucose assay kit (GAHK20), hydrazine sulfate salt, $\beta$-nicotinamide adenine dinucleotide hydrate $(\beta-N A D ;$ N7004), L-lactic dehydrogenase (From bovine heart; L2625), perchloric acid (PCA) solution, and hydrochloric acid $(\mathrm{HCl})$ solution were purchase from SigmaAldrich Co. LLC. (St. Louis, MO, USA). Deionized water was obtained from a Milli-Q Water Purification Equipment (Millipore SAS, Molsheim, Alsace, France).

\section{Preparation of samples and experimental design}

Five-heads of Hanwoo (Korean cattle) heifers were raised until 40-mon-old at the Hanwoo Experimental Station, National Institute of Animal Science, Republic of Korea, slaughtered, and chilled overnight at $1^{\circ} \mathrm{C}$. The loin, striploin, top round, and eye of round were collected from their left carcasses ( 1 head: grade $1^{++} \mathrm{B}, 1$ head: $1^{+} \mathrm{B}, 1$ head: $1^{+} \mathrm{C}, 1$ head: $1 \mathrm{C}$, and 1 head: 2C) $24 \mathrm{~h}$ post-slaughter and the subcutaneous fat and connective tissue were removed. Following pulverization with liquid nitrogen, the lean meat (100-200 g) from all beef parts were stored at $-80^{\circ} \mathrm{C}$ before experiments. Duplicate about $18 \mathrm{~g}$ of meat powders were weighed into $\Phi 25 \times 95 \mathrm{~mm}$ glass vials (03-338J, Thermo Fisher Scientific Inc., Waltham, USA), divided by cooking conditions into two groups, and heated in either with $100^{\circ} \mathrm{C}$ water bath (Wet-cooking treatment; BS-21, Jeio Tech Co., Ltd., Korea) or $180^{\circ} \mathrm{C}$ household electric oven (Dry-cooking treatment; EON-C301S, Tongyang Magic Co., Korea) until attained to about $80^{\circ} \mathrm{C}$ of average internal temperature (305B Digital Thermometer, Tecpel Co., Ltd., Taiwan). Immediately after cooled in ice water, all samples were utilized in experimental measurements.

\section{Macroglycogen and proglycogen contents measure- ment}

Macroglycogen (MG) and proglycogen (PG) contents were performed according to the procedure established by Adamo and Graham (1998). With $0.8 \mathrm{~mL}$ of ice-cooled PCA (3 M, USA) using a spatula, $0.1 \mathrm{~g}$ of samples were gently mixed, placed on ice in a refrigerator $\left(2^{\circ} \mathrm{C}\right)$ for 30 $\mathrm{min}$, and then centrifuged for $20 \mathrm{~min}$ at $2^{\circ} \mathrm{C}, 3,000 \mathrm{rpm}$ (Avanti J-E Centrifuge, Beckman Coulter, Inc., USA). For the measurement of MG content, the supernatants (100 $\mu \mathrm{L}$ ) were boiled with $1 \mathrm{~mL}$ of $1 \mathrm{~N} \mathrm{HCl}$ for $120 \mathrm{~min}$, to break down the glycogen to glucose, combined with $\mathrm{pH}$ indicator (BTB-phenolphthalein), and then neutralized using $2 \mathrm{M}$ trizma base. The PG content was determined in the sediments by the same process to MG content. Following filtration through $0.45 \mu \mathrm{m}$ syringe filter, as described by Kunst et al. (1984), the final solutions were reacted with $1 \mathrm{~mL}$ of glucose assay reagent $(1.5 \mathrm{mM} \beta$ NAD-1 mM ATP-1 U/mL hexokinase-1 U/mL glucose-6phosphate dehydrogenase) for $30 \mathrm{~min}$ at $37^{\circ} \mathrm{C}$ and measured at $340 \mathrm{~nm}$ using an UV/Visible spectrophotometer (ProteomeLab DU-800, Beckman Coulter, Inc., USA). The results were calculated as $\mu \mathrm{mol}$ of glucose per $\mathrm{g}$ of meat with millimolar extinction coefficient $\left(6.22 \mathrm{mM}^{-1} \mathrm{~cm}^{-1}\right)$ of $\beta$-NADH.

\section{Free glucose content measurement}

Free glucose content was measured using a glucose assay kit with the hexokinase method described by Kunst et al. (1984). Samples were mixed with cold PCA on ice using an Ultra-Turrax (T25 Digital, Ika Werke GmbH \& Co., Germany) for $30 \mathrm{~s}$ at $13,500 \mathrm{rpm}$. The homogenates were centrifuged for $20 \mathrm{~min}$ at $2^{\circ} \mathrm{C}, 3,000 \mathrm{rpm}(\mathrm{J}-20 \mathrm{XP}$ Centrifuge, Beckman Coulter, Inc., USA) before filtering through $0.45 \mu \mathrm{m}$ syringe filter. After mixed with glucose assay reagent, the filtrates were incubated for $30 \mathrm{~min}$ at $37^{\circ} \mathrm{C}$ and spectrophotometrically analyzed at $340 \mathrm{~nm}$. The results were expressed as $\mu \mathrm{mol}$ of glucose per $\mathrm{g}$ of meat.

\section{Lactate content determination}

Lactate content was determined with the process reported by Gutmann and Wahlefeld (1974). Briefly, following centrifugation for $20 \mathrm{~min}$ at $2^{\circ} \mathrm{C}, 11,600 \mathrm{rpm}$ (SCR-20A Himac Centrifuge, Hitachi Koki Co., Ltd., Japan), PCA extracts of samples were filtered through $0.45 \mu \mathrm{m}$ syringe filter and mixed with $3.6 \mathrm{~mL}$ of $0.2 \mathrm{M}$ hydrazine buffer (pH 9.6) and $200 \mu \mathrm{L}$ of $40 \mathrm{mM} \beta-\mathrm{NAD}$, and $100 \mu \mathrm{L}$ of 
$800 \mathrm{U} / \mathrm{mL}$ L-lactic dehydrogenase, and then incubated at $37^{\circ} \mathrm{C}$. The absorbance recordings $(340 \mathrm{~nm})$ were expressed as $\mathrm{mg}$ of lactate per $\mathrm{g}$ of meat with millimolar extinction coefficient of $\beta$-NADH.

\section{Statistical analysis}

All data from experimental parameters were analyzed by Analysis of Variance (ANOVA) of SPSS (2011) program and indicated as means \pm standard deviation (SD). Duncan's multiple range tests were conducted to compare the significant differences among the means of treatments at $p<0.05$.

\section{Results and Discussion}

\section{Macroglycogen and proglycogen contents}

The glycogen in animal muscles is classified into two types, i.e., macroglycogen and proglycogen (Lomako et al., 1991, 1993). The macroglycogen (MW: 10,000 kDa) is found in muscles at a high proportion to protein (about $0.4 \%$ ) and easily dissolves in acid solution. On the other hand, the proglycogen (MW: $400 \mathrm{kDa}$ ) exists in muscles at a low proportion to protein (about 10\%) and hardly melts in acid solution. The effect of cooking condition on the macroglycogen content in loin, striploin, top round, and eye of round from Hanwoo (Korean cattle) was presented in Fig. 1. In all four meat parts, there were no significant $(p>0.05)$ differences for macroglycogen content between the wet- and dry-cooking treatments. The wetor dry-cooked loin, striploin, and top round significantly $(p<0.05)$ contained higher macroglycogen content compared with the cooked eye of round. Regardless of meat parts, the proglycogen content (Fig. 2) was also not significantly different by cooking condition. Within the drycooking treatment, the both loin and striploin significantly $(p<0.05)$ had higher proglycogen content than the eye of round. Thus, cooking condition did not influence on the macroglycogen and proglycogen contents in beef muscles from Hanwoo. Till the present, no data on effect of cooking condition on not only total glycogen but two types of glycogen have been reported. However, this result is similar with a previous finding of Ferguson et al. (2008), who observed that the both macroglycogen and proglycogen contents of M. longissimus thoracis et lumborum was higher than those of both M. semimembranosus and M. semitendinosus in lamb.

\section{Free glucose content}

The effect of cooking condition on the free glucose con-

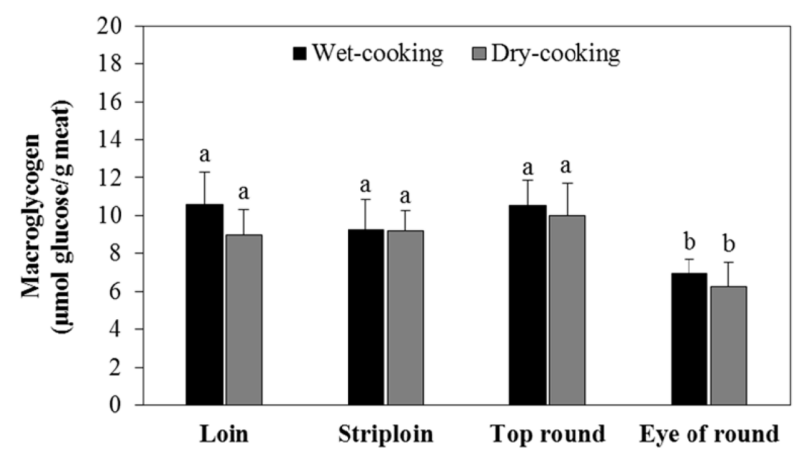

Fig. 1. Effect of cooking condition on the macroglycogen content in various muscles from Hanwoo (Korean cattle). Values are means $\pm S D$. ${ }^{\text {a-b }}$ Different letters indicate significant differences among treatments $(p<0.05)$.

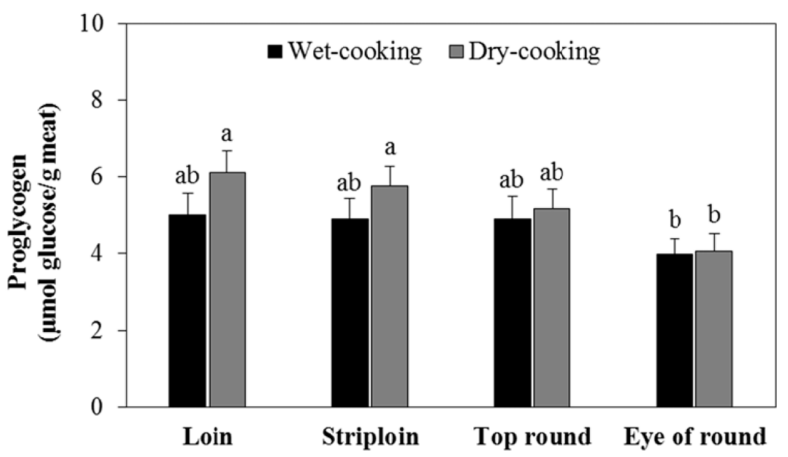

Fig. 2. Effect of cooking condition on the proglycogen content in various muscles from Hanwoo (Korean cattle). Values are means \pm SD. ${ }^{\text {a-b }}$ Different letters indicate significant differences among treatments $(p<0.05)$.

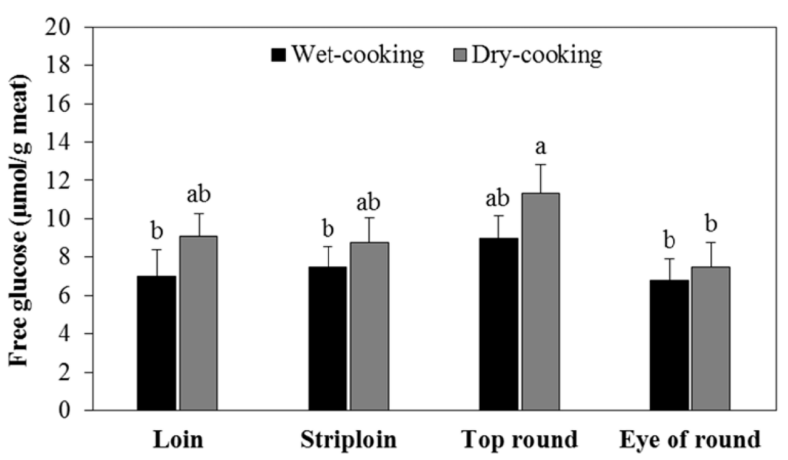

Fig. 3. Effect of cooking condition on the free glucose in various muscles from Hanwoo (Korean cattle). Values are means \pm SD. ${ }^{\text {a-b }}$ Different letters indicate significant differences among treatments $(p<0.05)$.

tent in Hanwoo beef muscles was indicated in Fig. 3. No significant differences were found for free glucose content between the wet- and dry-cooking treatments, but the dry-cooking treatment showed the tendency including higher free glucose content compared with the wet-cook- 
ing treatment. Within the wet-cooking treatment, the top round significantly $(p<0.05)$ had higher free glucose content than the eye of round. Cooking treatment causes not only the water loss (cooking juice) but also the spill of water-soluble flavor precursors for meat (Chikuni et al., 2002). Besides, strong cooking condition leaks more cooking juice, which can lead to the loss of more watersoluble precursors (Sasaki et al., 2007; Vasanthi et al., 2007). Thus, in our study, the difference for glucose content by cooking condition would be probably the reason why the dry-cooking treatment resulted in lower cooking juice compared with the wet-cooking treatment. This finding is supported by a report of Mora and others (2011), who found that the low steam-cooking treatment showed lower cooking juice loss than the high steam-cooking treatment. In addition, Alfaia and others (2010) observed that grilling caused about $7.3 \%$ lower cooking loss than boiling, leading to about $6.9 \%$ and $14.3 \%$ higher true retention values [ $\{$ (nutrient content per $\mathrm{g}$ of cooked meat $\times \mathrm{g}$ of meat after cooking)/(nutrient content per $\mathrm{g}$ of raw meat $\times \mathrm{g}$ of meat before cooking) $\} \times 100$ ] of moisture and total lipids in beef.

\section{Lactate content}

The lactate content (Fig. 4) also indicated higher trend in the dry-cooking treatment than in the wet-cooking treatment. In particular, significant $(p<0.05)$ differences for lactate content were observed in the loin, striploin, and eye of round by cooking condition. In addition, the wetor dry-cooked top round showed higher lactate content than the other muscles. In postmortem animal muscles, the lactate lowers $\mathrm{pH}$ value (Greaser, 1986), and serves the sour taste to cooked meat (Mottram, 1991). Because, unfortunately, in some of studies (Meiner et al., 2007, 2009 ), only effects of aging and genetics on the lactate

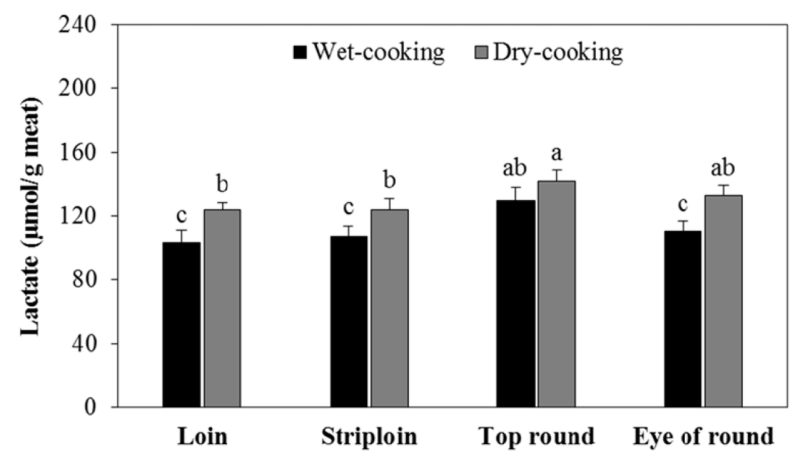

Fig. 4. Effect of cooking condition on the lactate content in various muscles from Hanwoo (Korean cattle). Values are means \pm SD. ${ }^{\text {a-c }}$ Different letters indicate significant differences among treatments $(p<0.05)$. content have been explained, it is not clear how cooking condition affects the lactate content. However, against findings of Chikuni et al. (2002), Mora et al. (2011), and Sasaki et al. (2007), we consider that the difference for lactate content may come from the difference for cooking loss between wet- and dry-cooking treatments.

\section{Conclusions}

The effect of cooking condition (wet- and dry-cooking treatments) on the water-soluble flavor precursors related to postmortem carbohydrate metabolisms in loin, striploin, top round, and eye of round from Hanwoo (Korean cattle) was investigated in this study. Cooking condition influenced on the amount of glycogen-metabolized derivatives in Hanwoo beef muscles. Especially, the dry-cooking treatment maintained higher free glucose and lactate contents than the wet-cooking treatment. Although the measurement of cooking loss was not conducted in this study, it is regarded that these differences for contents of water-soluble precursors would originate in the difference for amount of cooking juice between two cooking conditions. So, further research is needed to be clear whether the dry-cooking treatment leads to lower cooking loss compared with the wet-cooking treatment.

\section{Acknowledgements}

This study was supported by 2011 2013 Postdoctoral Fellowship Program of National Institute of Animal Science, Rural Development Administration, Korea.

\section{References}

1. Adamo, K. B. and Graham, T. E. (1998) Comparison of traditional measurements with macroglycogen and proglycogen analysis of muscle glycogen. J. Appl. Physiol. 84, 908-913.

2. Adhikari, K., Keene, M. P., Heymann, H., and Lorenzen, C. L. (2004) Optimizing beef chuck flavor and texture through cookery methods. J. Food Sci. 69, 174-180.

3. Alfaia, C. M. M., Alves, S. P., Lopes, A. F., Fernandes, M. J. E., Costa, A. S. H., Fontes, C. M. G. A., Castro, M. L. F., Bessa, R. J. B., and Prates, J. A. M. (2010) Effect of cooking methods on fatty acids, conjugated isomers of linoleic acid and nutritional quality of beef intramuscular fat. Meat Sci. 84, 769-777.

4. Belk, K. E., Miller, R. K., Evans, L. L., Liu, S. P., and Acuff, G. R. (1993) Flavor attributes and microbial levels of fresh beef roasts cooked in varying foodservice methodology. $J$. Muscle Foods 4, 321-337.

5. Bryhni, E. A., Byrne, D. V., Rødbotten, M., Claudi-Magnus- 
sen, C., Agerhem, H., Johansson, M., Lea, P., and Martens, M. (2002) Consumer perceptions of pork in Denmark, Norway and Sweden. Food Qual. Prefer. 13, 257-266.

6. Calkins, C. R. (2002) Sensory differences among the beef value cuts. Proc. Am. Meat Sci. Assoc. Rec. Meat Con., Univ. of Missouri, Columbia, MO, USA.

7. Chikuni, K., Sasaki, K., Emori, T., Iwaki, F., Tani, F., Nakajima, I., Muroya, S., and Mitsumoto, M. (2002) Effect of cooking on the taste- and flavor-related compounds in pork. Jpn. J. Swine Sci. 39, 191-199.

8. Cho, S. H., Kim, J. H., Kim, J. H., Seong, P. N., Park, B. Y., Kim, D. H., Lee, J. M., and Ahn, C. N. (2008) Prediction of palatability grading scores analyzed with sensory data of Hanwoo bull and steer beef. Proc. Ann. Cong. Korean Soc. Anim. Sci. Technol., Seoul National Univ., Seoul, Korea, pp. 136.

9. Ferguson, D. M., Daly, B. L., Gardner, G. E., and Tume, R. K. (2008) Effect of glycogen concentration and form on the response to electrical stimulation and rate of post-mortem glycolysis in ovine muscle. Meat Sci. 78, 202-210.

10. Greaser, M. L. (1986) Conversion of muscle to meat. In: Muscle as food. Bechtel, P. J. (ed) Academic Press, Inc., Orlando, USA, pp. 37-102.

11. Gutmann, I. and Wahlefeld, A. W. (1974) L-(+)-lactate: Determination with lactate dehydrogenase and NAD. In: Methods of enzymatic analysis. Bergmeyer, H. U. (ed) Academic Press, Inc., NY, USA. Vol. 3, pp. 1464-1468.

12. Hornstein, I. and Crowe, P. F. (1960) Meat flavor chemistry: Flavour studies on beef and pork. J. Agr. Food Chem. 8, 494498.

13. Koutsidis, G., Elmore, J. S., Oruna-Concha, M. J., Campo, M. M., Wood, J. D., and Mottram, D. S. (2008a) Water-soluble precursors of beef flavour: I. Effect of diet and breed. Meat Sci. 79, 124-130.

14. Koutsidis, G., Elmore, J. S., Oruna-Concha, M. J., Campo, M. M., Wood, J. D., and Mottram, D. S. (2008b) Water-soluble precursors of beef flavor: II. Effect of post-mortem conditioning. Meat Sci. 79, 270-277.

15. Kunst, A., Draeger, B., and Ziegenhorn, J. (1984) Glucose: UVmethods with hexokinase and glucose-6-phosphate dehydrogenase. In: Methods of enzymatic analysis. Bergmeyer, H. U (ed) Academic Press, Inc., NY, USA. Vol. 6, pp. 163-172.

16. Lomako, J., Lomako, W. M., and Whelan, W. J. (1991) Proglycogen: A low-molecular-weight form of muscle glycogen. FEBS Lett. 279, 223-228.

17. Lomako, J., Lomako, W. M., Whelan, W. J., Dombro, R. S., Neary, J. T., and Norenberg, M. D. (1993) Glycogen synthesis in the astrocyte: From glycogenin to proglycogen to glycogen. FASEB J. 7, 1386-1393.

18. MacLeod, G. (1986) The scientific and technological basis of meat flavours. In: Developments in food flavours. Birch, G. G. and Lindley, M. G. (eds) Elesevier Applied Science, London, UK, pp. 191-223.

19. MacLeod, G. (1994) The flavour of beef. In: The flavor of meat and meat products. Shahidi, F. (ed) Blakie, Glasgow, USA, pp. 4-37.

20. McKenna, D. R., Lorenzen, C. L., Pollok, K. D., Morgan, W.
W., Mies, W. L., Harris, J. J., Murphy, R., McAdams, M., Hale, D. S., and Savell, J. W. (2004) Interrelationships of breed type, USDA quality grade, cooking method, and degree of doneness on consumer evaluations of beef in Dallas and San Antonio, Texas, USA. Meat Sci. 66, 399-406.

21. Meinert, L., Andersen, L. T., Bredie, W. L. P., Bjergegaard, C., and Aaslyng, M. D. (2007) Chemical and sensory characterization of pan-fried pork flavor: Interactions between raw meat quality, ageing and frying temperature. Meat Sci. 75, 229-242.

22. Meinert, L., Tikk, K., Tikk, M., Brockhoff, P. B., Bredie, W. L. P., Bjergegaard, C., and Aaslyng, M. D. (2009) Flavour development in pork. Influence of flavor precursors concentrations in longissimus dorsi from pigs with different raw meat qualities. Meat Sci. 81, 255-262.

23. Miller, M. F., Kerth, C. R., Wise, J. W., Lansdell, J. L., Stowell, J. E., and Ramsey, C. B. (1997) Slaughter plant location, USDA quality grade, external fat thickness and aging time effects on sensory characteristics of beef loin strip steak. $J$. Anim. Sci. 75, 662-667.

24. Mora, B., Curti, E., Vittadini, E., and Barbanti, D. (2011) Effect of different air/steam convection cooking methods on turkey breast meat: Physical characterization, water status and sensory properties. Meat Sci. 88, 489-497.

25. Mottram, D. (1991) Meat. In: Volatile compounds in foods and beverages. Maarse, H. (ed) Marcel Dekker, Inc., NY, USA, pp. 107-177.

26. Pethick, D. W., Rowe, J. B., and Tudor, G. (1995) Glycogen metabolism and meat quality. Rec. Adv. Anim. Nutr. Aust. July, 97-102.

27. Sasaki, K., Motoyama, M., and Mitsumoto, M. (2007) Changes in the amounts of water-soluble umami-related substances in porcine longissimus and biceps femoris muscles during moist heat cooking. Meat Sci. 77, 167-172.

28. Savell, J. W., Branson, R. E., Cross, H. R., Stiffler, D. M., Wise, J. W., Griffin, D. B., and Smith, G. C. (1987) National consumer retail beef study: Palatability evaluations of beef loin steaks that differed in marbling. J. Food Sci. 52, 517-519.

29. Shahidi, F. (1998) Flavor of muscle foods: An overview. In: Flavor of meat, meat products, and seafoods. Shahidi, F. (ed) Blackie Academic and Professional, London, UK, pp. 1-4.

30. SPSS. (2011) PASW Statistics 21. Statistical Package for the Social Sciences Incorporated, Illinois, USA.

31. Stezer, A. J., Cadwallader, K., Singh, T. K., Mckeith, F. K., and Brewer, M. S. (2008) Effect of enhancement and ageing on flavor and volatile compounds in various beef muscles. Meat Sci. 79, 13-19.

32. Streff, B. A., Wulf, D. M., and Maddock, R. J. (2003) The effect of USDA quality grade, deep marination, and degreeof-doneness on palatability of gas grilled beef steaks from seven different muscles. Proc. Am. Meat Sci. Assoc. Rec. Meat Con., Univ. of Missouri, Columbia, MO, USA.

33. Vasanthi, C., Venkataramanujam, V., and Dushyanthan, K. (2007) Effect of cooking temperature and time on the physicchemical, histological and sensory properties of female carabeef (buffalo) meat. Meat Sci. 76, 274-280.

(Received 2013.9.30/Revised 2013.11.26/Accepted 2013.11.27) 